\title{
Wormlike Micelles of Block Copolymers: Measuring the Linear Density by AFM and Light Scattering
}

Isaac LaRue, Mireille Adam, Marcelo da Silva, Sergei S. Sheiko, and Michael Rubinstein

Department of Chemistry, University of North Carolina at Chapel Hill, Chapel Hill, NC 27599-3290

e-mail:madam@email.unc.edu,sergei@email.unc.edu

\section{Supporting information:}

It is known that PS-PI diblocks prepared by anionic polymerization may contain small fraction of linear PS. Here we present a comparative analysis of two PS-b-PI samples of approximately the same composition (the numbers in brackets indicate molecular weights of the blocks) which corresponds to the studied 40-10 sample.

Sample 1: PS(39800)-b-PI(11400)

Sample 2: PS(39800)-b-PI(11700)

Figure 1a and Figure 1b show molecular weight distributions obtained by gel permeation chromatography (GPC) in THF of Samples 1 and 2, respectively. Both samples show relatively narrow and monomodal elution curves. This shows that the samples are quite pure. However, in our case, it is difficult to detect the small fraction of the PS homopolymer because of the small difference between the diblock molecular weight $(51.2 \mathrm{kDa})$ and the molecular weight of the PS homopolymer $(39.8 \mathrm{kDa})$.

More precise analysis can be done by static and dynamic light scattering measurements in cyclohexane. Figure 2a depicts intensity vs. particle diameter measured for Sample 1 at a higher temperature of $29^{\circ} \mathrm{C}$ obtained using Brookhaven's CONTIN fit from dynamic light scattering. The curve shows only one peak with a hydrodynamic diameter of approximately $10 \mathrm{~nm}$. If one decreases the temperature ${ }^{1}$ down to $20^{\circ} \mathrm{C}$ (i.e. below the theta temperature of polystyrene in cyclohexane), a second peak emerges with a diameter of about $644 \mathrm{~nm}$. We believe this peak corresponds to particles of precipitated PS homopolymer. Even though the peak at larger radius looks big, one must note that the Yscale is in relative intensities and that the scattering of a few large particles will have a much higher intensity than the same number of particles of a small size. Since the intensity for the particles of larger diameter is not that much higher than the intensity for the diblock, the actually amount of homopolymer is small, yet significant. Thus we conclude that Sample 1 contains a small fraction of PS homopolymer.

Figure 3a,b depicts two intensity-vs.-particle diameter curves for Sample 2, which were also measured at $29^{\circ} \mathrm{C}$ and $20^{\circ} \mathrm{C}$, respectively. In contrast to Sample 1, at low temperatures the second peak, which appears slightly at a diameter of $400 \mathrm{~nm}$, is so small 
that it is barely observable. Again since large particles scatter more intensely than small ones, the amount of homopolymer is found to be so minuscule that it is insignificant. For the experiments presented in this paper the same characterization was carried out on sample 40-10 and no significant amount of homopolymer was found.

Figure 1a. GPC data of Sample 1 PS(39800)-b-PI(11400).

Poly(styrene-b-isoprene)

\section{GPC Data}

Sowent: THF

Columns: PSS SDV 5 $10^{3}, 10^{5}, 10^{8} \mathrm{~A}, 8 \times 300 \mathrm{~mm}$

Data aquisition system: PSS WINGPC sofvare lot no.zpspi24102

Temperature: $25^{\circ} \mathrm{C}$
PS-PI Total Weight Average Molecular Weight
$M_{t}=53400 D^{i}$
PS-PI Tolal Number Averago Molecular Weight
PD1
$M_{1}=51200 \mathrm{D}^{4}$
precursar:ps31102
PS Weight AV. Molecular Weight
$\mathrm{D}=1,05$
PS Number Av. Molecular Weight
$M_{1}=40500 \mathrm{DF}^{2}$
$\mathrm{MH}_{\mathrm{H}}=38800 \mathrm{D}^{2}$
$\mathrm{D}=1,03$
PDI
Pl Number Av. Molecular Weight
$M=11400 D^{5}$

"Messured us a PS-PI copolymer calibrabiancurve using PSS WNGPC 6.2 copolymer modula

7 hteasured is a PS cablation cure using PSS WINPGPC 6.2

Gabculated from $\square$ and $n$

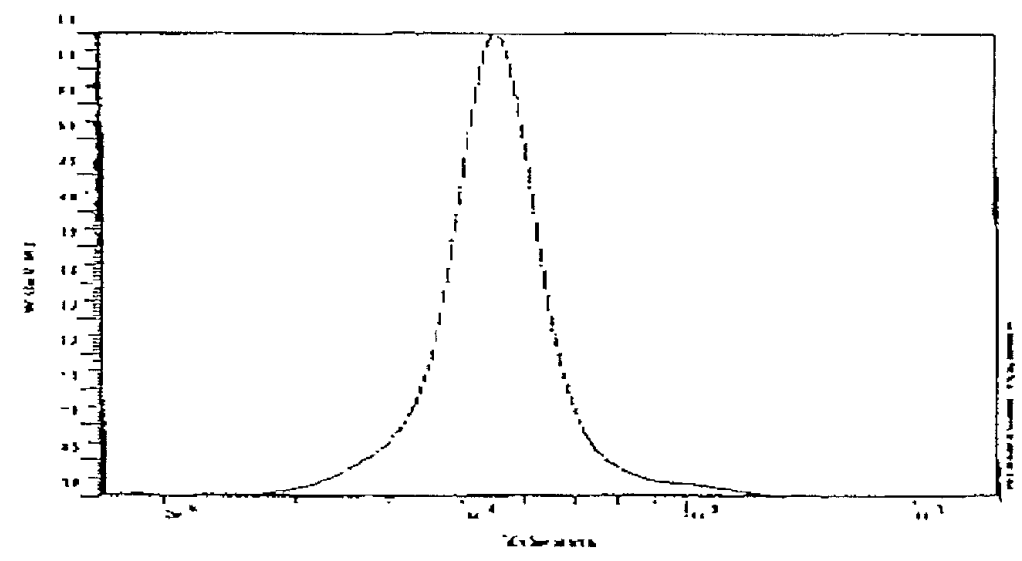


Figure 1b. GPC data of Sample 2 PS(39800)-b-PI(11700).

Poly(styrene-b-isoprene)

lot no.:pspi26102

GPG Data

Solvent: THF

Columns: PSS SDV $5 \mu 10^{\beta}, 10^{5}, 10^{\mathrm{B} A}, 8 \times 300 \mathrm{~mm}$

Temperalure: $25^{\circ} \mathrm{C}$

Data aquisition system: PSS WINGPC software

PS-PI Total Weight Avergge Molecular Weight $\quad M_{r r}=53200 D^{\prime}$

PS-PI Total Number Average Molecular WVeight $\quad M_{n}=51500 D^{1}$

PDI

$\mathrm{D}=1,05$

precursor.ps31to2

PS Weight AY. Molecular Weight

PS Number Av. Mholecular Weight

$M_{x}=40900 D^{2}$

PDI

$M=39800 D^{2}$

$D=1,03$

PI Number Av. Molecular Weight

$M_{h}=11700 D^{3}$

" Measured vs a PS-PI copolymer calbrationcurve using PSS WINGPC 6.2 copolymer module

2 Measured vs a FS carbation cure usirg PSS MINPGPC 8.2

"Calculated from" and ${ }^{\text {D }}$

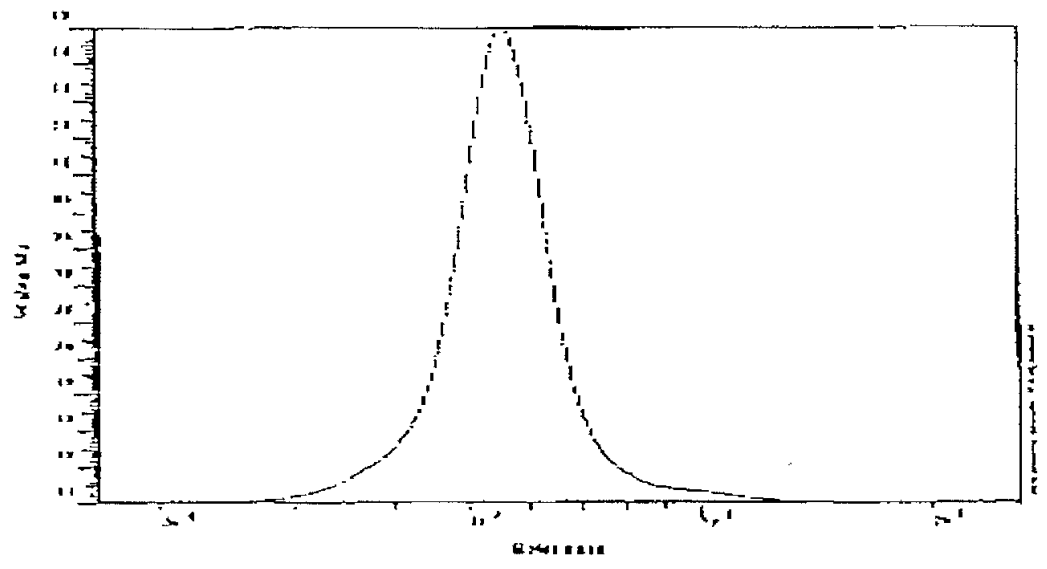


Fig 2. Light scattering of polymer Sample 1 [PS(39800)-b-PI(11400)] in Cyclohexane at two different temperatures: a - 29C and b-20C. The data are presented as intensity vs. particle diameter.

(a) $\mathrm{T}(\mathrm{C})=29, \mathrm{C}(\mathrm{g} / \mathrm{mol})=0.019239$

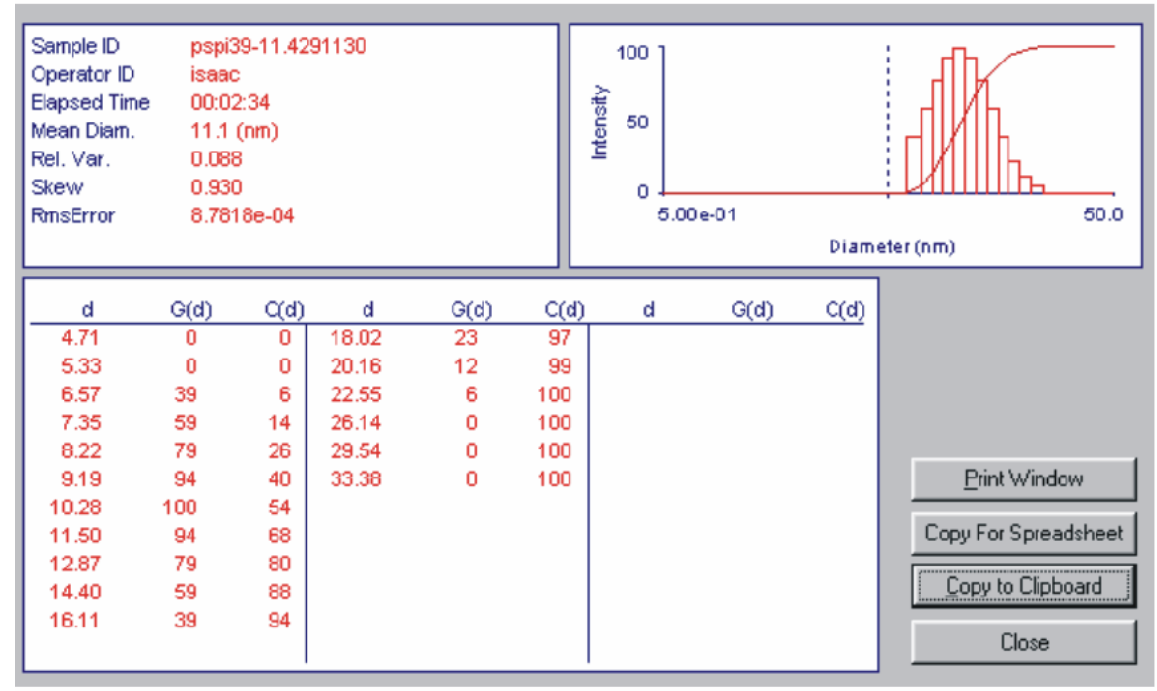

\section{(b) $\mathrm{T}(\mathrm{C})=20, \mathrm{C}(\mathrm{g} / \mathrm{mol})=0.019239$}

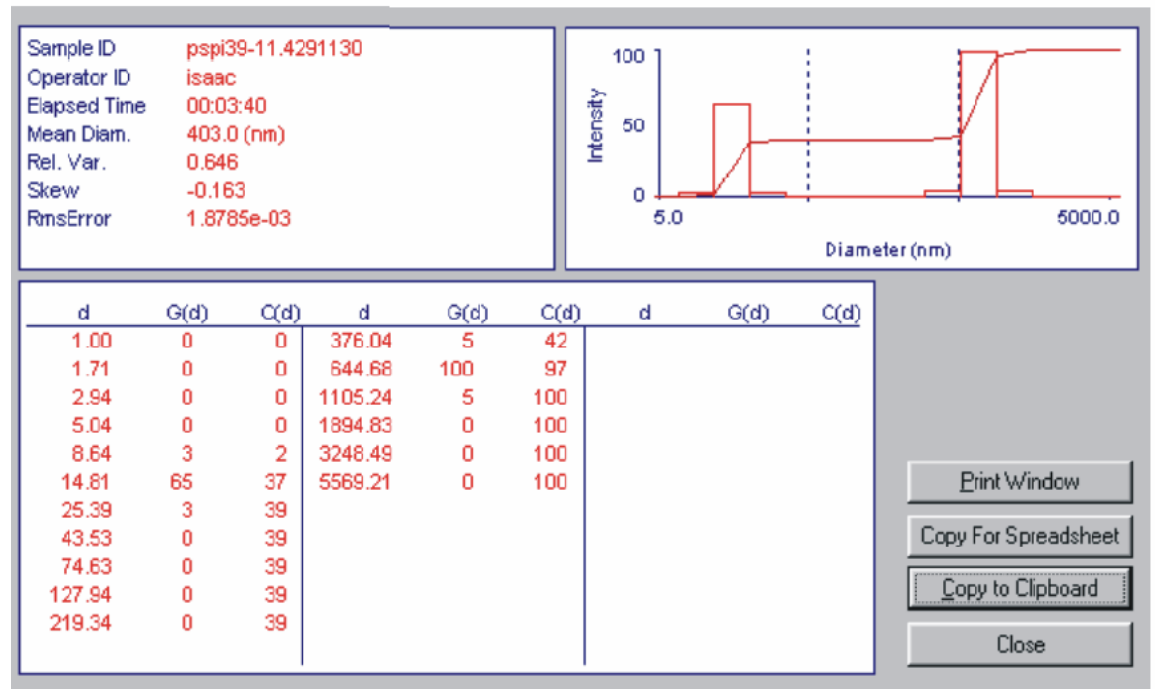


Fig 3. Light scattering of Sample 2 [PS(39800)-b-PI(11700)] in Cyclohexane at two different temperatures: $\mathrm{a}-29 \mathrm{C}$ and b - 20C. The data are presented as intensity vs. particle diameter.

(a) $\mathrm{T}(\mathrm{C})=29, \mathrm{C}(\mathrm{g} / \mathrm{mol})=0.021174$

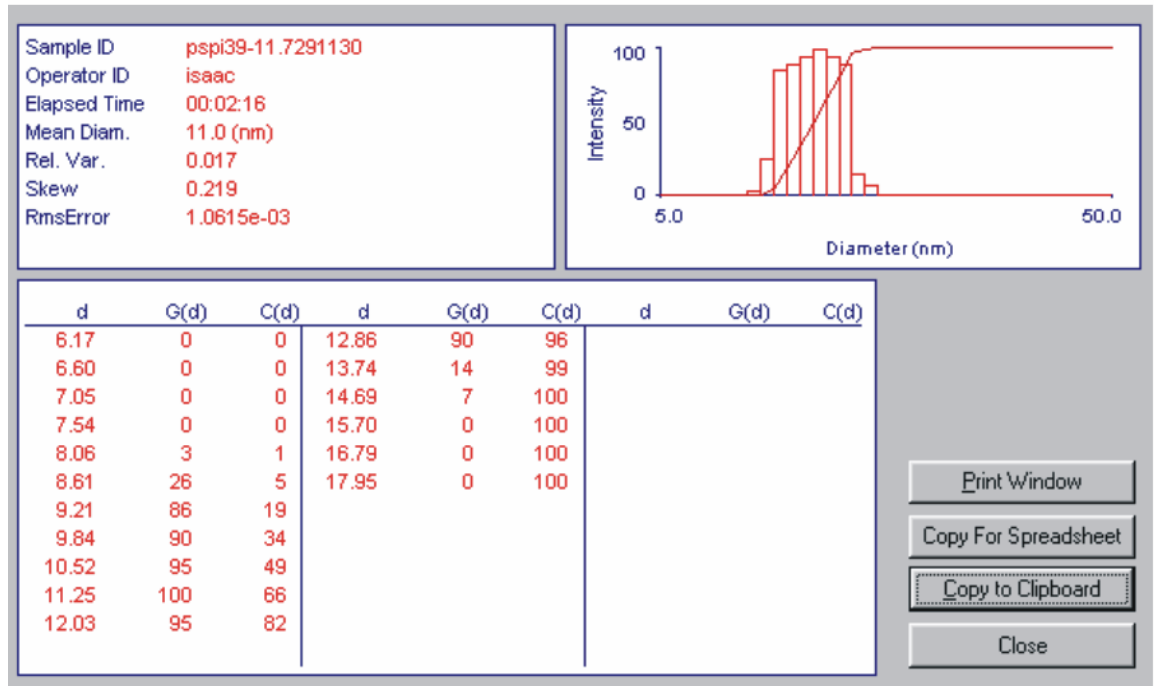

(b) $\mathrm{T}(\mathrm{C})=20, \mathrm{C}(\mathrm{g} / \mathrm{mol})=0.021174$

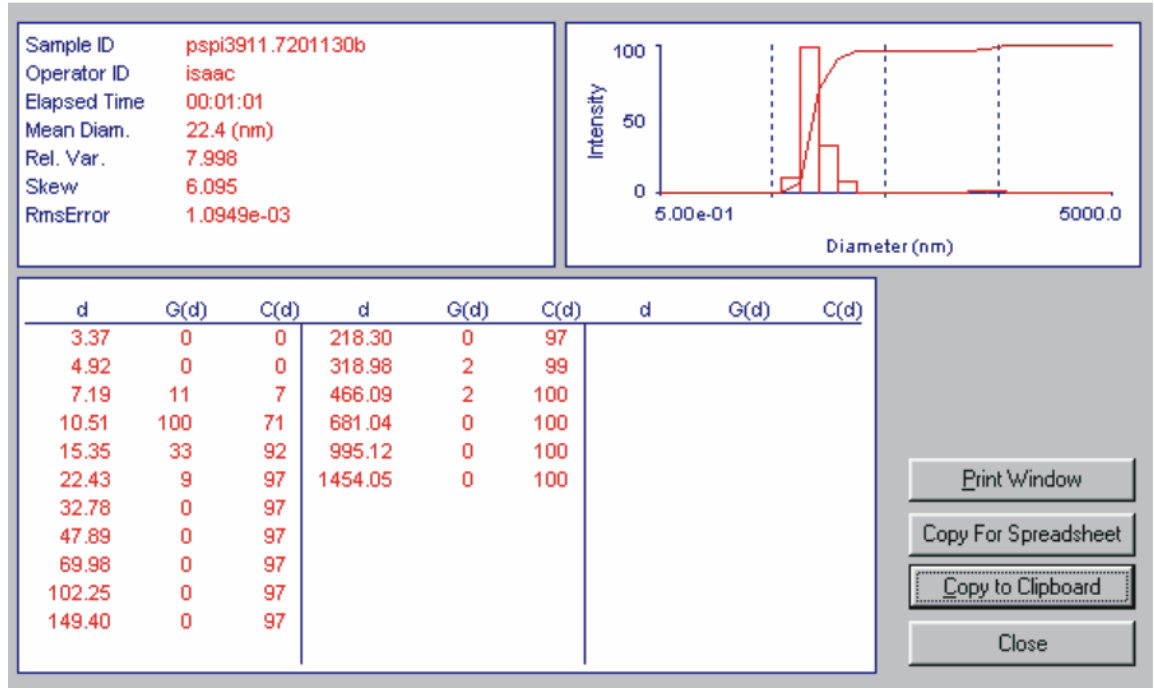

\footnotetext{
${ }^{1}$ Note that PS-PI diblocks remain soluble, because cyclohexane is a good solvent for the PI block.
} 